\title{
Sentidos do cuidado: a perspectiva de cuidadores de homens com câncer
}

\author{
Suellen Santos Lima de Almeida - Centro de Pesquisas René Rachou, Belo Horizonte/MG, Brasil \\ Alberto Mesaque Martins - Centro de Pesquisas René Rachou, Belo Horizonte/MG, Brasil \\ Adryene Milanez Rezende - Centro de Pesquisas René Rachou, Belo Horizonte/MG, Brasil \\ Virginia Torres Schall - Centro de Pesquisas René Rachou, Belo Horizonte/MG, Brasil \\ Celina Maria Modena - Escola de Enfermagem UFMG, Belo Horizonte/MG, Brasil
}

\begin{abstract}
Resumo
Há, na atualidade, uma tendência para que os cuidados aos pacientes com câncer sejam realizados no âmbito familiar. Nesse sentido, o presente estudo buscou compreender como os cuidadores de homens em tratamento oncológico significam a experiência do cuidado. Foram realizadas entrevistas narrativas com 10 cuidadores de homens com câncer em um hospital público, especializado em oncologia, na cidade de Belo Horizonte-MG. Na análise, realizada à luz do referencial fenomenológico heideggeriano, pode-se conhecer o sentido que os cuidadores atribuem ao câncer, o significado atribuído à experiência de ser cuidador e os sentidos do cuidar. Considera-se que conhecer os sentidos que os cuidadores atribuem ao seu fazer possibilita pensar em intervenções direcionadas às necessidades desses sujeitos, visando melhorar sua qualidade de vida.

Palavras-chave: Cuidadores; Sentido; Fenomenologia existencial
\end{abstract}

Senses of care: the perspective of caregivers of people with cancer

\begin{abstract}
There is currently a tendency for the care of patients with cancer to be performed within the family. In that sense, this study aimed to understand how caregivers of men in Oncology treatment mean the experience of care. Narrative interviews were conducted with 10 caregivers of men's with cancer in a public hospital specializing in Oncology in the city of Belo Horizonte-MG-Brasil. The analysis conducted through the Heideggerian phenomenological pointed to the meaning that caregivers attribute to cancer, the meaning attributed to the experience of being a caregiver and the meaning of care. To understand the meanings that the caregivers attribute to their activities allow interventions directed to the needs of these subjects, favoring their quality of life.

Keywords: Caregivers; Sense; Existential phenomenology
\end{abstract}

\section{Sentidos de la atención: la perspectiva de los cuidadores de las personas con cáncer}

\begin{abstract}
Resumen
Actualmente, hay una tendencia a que el cuidado de pacientes con cáncer se realize en suyas familias. Este estudio buscó comprender cómo los cuidadores de los hombres sometidos a tratamiento contra el cáncer significan la experiencia del Cuidado. Se realizaron entrevistas narrativas con los 10 cuidadores en un hospital público especializado en oncología, en la ciudad de Belo Horizonte-MG-Brasil. Por el análisis realizado, en la perspectiva de la fenomenología heideggeriana, se puedo conocer el significado que los cuidadores atribuyen al cáncer, el significado atribuido a la experiencia de ser un cuidador y los sentidos de cuidado. Se considera que conocer los sentidos que los cuidadores atribuyen a su actividad permite que intervenciones dirigidas a las necesidades de estas personas sean posibles, para mejorar su calidad de vida.

Palabras clave: Cuidadores; Sentido; Fenomenología existencial.
\end{abstract}

Nos últimos anos, tendo em vista a elevada incidência e prevalência do câncer na população masculina mundial, observa-se a necessidade de reflexão acerca do processo saúde-adoecimentocuidado de homens com câncer. A dificuldade de mobilização dos homens para as práticas de prevenção e diagnóstico precoce das neoplasias, bem como a menor adesão desse público ao tratamento oncológico, apontam para implicações dos modos de vida dos homens na maneira como se vinculam as ações de cuidado (Xavier, Ataíde, Pereira \& Nascimento, 2010).

Estudos apontam que o diagnóstico de câncer coloca os homens diante de uma situação de limitações, fragilidades e necessidades de cuidados que se contrapõem aos modos como eles aprenderam a exercer a masculinidade, com seus significados de invulnerabilidade, força e provedor (Xavier \& cols.,
2010). A constante necessidade de cuidados imposta pelo adoecimento implica uma redistribuição dos papéis familiares, fazendo com que o "homemcuidador" passe a ocupar uma posição de "homemcuidado" (Dazio, Sonobe \& Zago, 2009).

Ao se pretender trabalhar com cuidadores, faz-se necessário compreender o que vem a ser cuidado. A filosofia existencial heideggeriana traz uma profunda reflexão sobre o assunto, apontando para seu sentido ontológico, enquanto constituinte do ser humano, define sua essência e determina a estrutura de sua prática (Heidegger, 2008).

Lançado no mundo, o homem tem que se fazer, construir sua existência num movimento constante de ter que ser, que é permeado pelo cuidado a si, aos outros e ao mundo (Critelli, 1996). Dessa forma, seja individual, seja coletivamente, o homem escolhe o que 
vai estar sob seus cuidados aproximando-se ou se afastando de seu mundo vivido, de seu interesse (Critelli, 1996). Por ser um modo em que a pessoa sai de si e se centra no outro, o cuidado tanto adquire a significação de desvelo e solicitude quanto a de preocupação e inquietação pelo outro ao qual nos sentimos envolvidos e afetivamente ligados (Heidegger, 2008).

Em situação de adoecimento por doenças como o câncer, que traz consigo a representação social de sofrimento, deterioração e morte (Souza, 2011), os significados que o cuidado adquire são somados às situações precedentes e às possibilidades que o mundo coloca ao homem, fazendo-o assumir sua condição de cuidador. Ao decidir agir-em-função-do-outro o ser se reestrutura e, junto ao outro, atualiza seu projeto existencial mediante a construção da nova identidade: a de cuidador (Ayres, 2004).

Ao se tornarem cuidadores, as pessoas compartilham suas percepções, emoções, sentimentos, valores e saberes como ser que está sob seus cuidados (Oliveira \& Carraro, 2011). Nesse sentido, pode-se dizer que o cuidador tem seu "ser-aî" envolvido com o paciente e, a partir do momento que assume o cuidado, passa a "ser-com-o-outro-que-está-morrendo", e essa relação sempre afeta de alguma maneira sua existência (Souza \& Boemer, 2005).

Diante desse cenário, a Organização Mundial de Saúde considera que a atenção dos profissionais de saúde se volte também para os cuidadores (WHO, 2011). Escutar os cuidadores, valorizar seu modo de cuidar, compreender os significados dessa atividade e compreender como o cuidado é realizado faz-se necessário para que, juntamente com os cuidadores, os profissionais de saúde realizem intervenções que considerem os aspectos físicos, psíquicos, sociais e espirituais envolvidos (Almeida, Savassi, Schall \& Modena, 2012). Nesse sentido, o presente estudo buscou compreender como os cuidadores de homens em tratamento oncológico significam a experiência do cuidado.

\section{Metodologia}

O presente estudo se ampara no referencial teórico e metodológico da Fenomenologia Existencial Heideggeriana, que busca a compreensão da experiência vivida para a interpretação e elaboração dos conhecimentos, enfatizando a dimensão existencial do viver e os significados atribuídos pelo individuo em seu estar no mundo (Heidegger, 2008).

Utilizou-se para a coleta de dados, a entrevista narrativa uma vez que essa técnica possibilita uma aproximação da vivência do sujeito pela rememoração de sua história pessoal sobre um período de tempo específico ou sobre um acontecimento particular (Breakwell, 2010).

Os participantes foram selecionados por meio de critérios de intencionalidade, a saber: ser acompanhante de um homem em tratamento oncológico na instituição; ser maior de 18 anos; estar acompanhando o paciente em seu processo de tratamento há pelo menos três meses; aceitar participar da pesquisa. Foram entrevistados 10 acompanhantes que se identificaram como cuidadores principais dos pacientes em tratamento oncológico em um hospital público, especializado em oncologia, localizado na cidade de Belo Horizonte, Minas Gerais. As entrevistas foram interrompidas seguindo-se o critério de saturação e singularidade dos discursos, conforme proposto por Minayo (2007).

Todos os cuidadores participantes do estudo fazem parte do grupo familiar do homem em tratamento oncológico, sendo um pai, cinco filhos(as) e quatro esposas. A idade dos cuidadores variou entre 27 e 65 anos. Seis cuidadores residiam no interior do estado e estavam na capital para acompanhar o paciente; os demais cuidadores eram provenientes da capital e da região metropolitana. A renda média familiar foi de dois salários mínimos.

Utilizou-se a pergunta norteadora "O que é cuidado para você?" Deixou-se que os participantes discorressem sobre o assunto e, à medida que falavam, outras questões foram sendo introduzidas, buscando compreender como os cuidadores significavam o cuidado; suas vivências de cuidadores e as implicações em suas vidas e as especificidades de se cuidar de um homem com câncer.

A pesquisa foi aprovada pelo Comitê de Ética em Pesquisa do Centro de Pesquisa René Rachou Fundação Oswaldo Cruz (Parecer 13/2011) e pelo Comitê de Ética em Pesquisa do hospital participante (Parecer 82/2011), considerando-se o disposto na Resolução 196/96, que dispõe sobre diretrizes para pesquisas em seres humanos no Brasil (Ministério da Saúde, 1996). Os entrevistados foram esclarecidos sobre a confidencialidade das informações prestadas e suas identidades foram substituídas por seu grau de parentesco com o paciente (filho, esposa...).

$\mathrm{Na}$ análise, realizada à luz da metodologia fenomenológica (Heidegger, 2008), buscaram-se as descrições organizadas do que está sendo vivido pelo sujeito. A organização das narrativas dos sentidos relacionados ao cuidar de homens em tratamento oncológico possibilitou construir os seguintes núcleos de sentidos: sentidos do câncer; sentidos atribuídos à experiência de ser cuidador; e ser cuidador de um homem com câncer. 


\section{Resultados e discussão}

Sentidos que os cuidadores atribuem ao câncer

Diante do diagnóstico de câncer de seu familiar, os cuidadores relataram suas vivências diante $\mathrm{O}$ confronto com o inesperado:

"A gente nunca pensa que pode acontecer na familia da gente [...] Ouve falar e tal. A gente nunca pensa que pode acontecer comigo ou com alguém mais próximo de mim" (Filha 1); "Por mais que a gente já tava por dentro que podia ser isso mesmo, mas pra mim foi um choque" (Filha 2); "Foi um choque para nós quando nós descobrimos que o nosso pai tava com essa doença [...] A família toda foi no fundo do poco [...]" (Filha 3); "Ai que deu essa doenca na biopsia. Foi dificil nos primeiros dias depois que a gente descobriu [...]" (Esposa 1).

Imerso em seu projeto existencial, o homem não pensa se tem ou não saúde, esta já está pressuposta (Deliberador \& Villela, 2010). Assim, a vivência da doença e do tratamento provoca um distanciamento da familiaridade e da habitualidade da existência e tanto os pacientes quanto seus cuidadores familiares passam a conviver com uma realidade inesperada.

Os cuidadores participantes deste estudo se referem ao câncer como "essa doença", demonstrando a dificuldade de nomeá-la. A pronúncia da palavra câncer em alguns grupos é considerada como um chamado da doença para si. Assim, a não nomeação do câncer pode apresentar-se como uma tentativa de afastar as implicações sociais do diagnóstico, bem como um meio de evitar que se adoeça desse mal (Veras, 2009)

Esses discursos também podem apontar para o estigma social do câncer, representado como algo invasivo, limitante, traumático, que acarreta em desfiguramento, dor, crise financeira, trauma emocional, perda das funções corporais e morte. $\mathrm{O}$ temor social relacionado ao câncer impede até mesmo que seu nome seja dito (Souza, 2011).

Alguns discursos apontam para a gravidade do estado de saúde do paciente:

[...] Ele já tá todo avançado e o médico já não tá dando muito tempo mais pra ele [...] Não que a gente quer que ele vai, mas vê ele gritando de dor, igual a gente vê. [...] Do jeito que en vi men pai, en pedi pra Deus dá pra ele o descanso [...] (Filha 3).

Pode-se inferir que quando facticidades como o câncer surgem na vida do sujeito e o confronta com a morte, podem até mesmo se tornar uma aliada, pois surge como uma alternativa para a cessação do sofrimento. $\mathrm{O}$ câncer é representado socialmente de forma mais intensa como um dos símbolos da morte (Souza, 2011). O medo que se tem em relação à doença não é o medo de simplesmente morrer, mas sim de se "morrer de câncer" (Barbosa, Francisco \& Eken,
2007). Ao se perceber como um ser-para-a-morte, o homem é chamado a considerar sua existência de uma forma mais própria, a se preocupar com sua existência, compreendendo sempre que a morte é o limite para suas possibilidades (Almeida, Rezende, Schall \& Modena, 2010). Imerso em seus afazeres, a morte apresenta-se como algo distante, impensável, no entanto independentemente do projeto que eleja para si, a morte é uma possibilidade que não é da escolha do Dasein $^{1}$, pois é uma possibilidade existencial (Heidegger, 2008).

\section{Sentido da experiência de ser cuidador}

Ser-cuidador é apontado pelos sujeitos como uma restrição de suas possibilidades existenciais:

Trabalhava. Aí eu larguei, né? No momento eu to só acompanhando ele. (Filha 1);

Largo tudo, largo tudo, igual en já larguei. Larguei tudo, larguei serviço, larguei festa, larguei tudo [...] eu era uma pessoa que... trabalhava, né? Trabalhava, tinha mais vida, mais assim entusiasmo com as coisas. Então o dia-a-dia, você vai perdendo o campo vai deixando as coisas. (Esposa 2)

(...) eu trabalhava num trailler, né? Meu mesmo, só que acabou por en tá cuidando dele, nesse exame e consulta então en tive que fechar o trailler pra mim tomar conta dele. Então eu não to podendo trabalhar porque eu tenho que ficar olhando ele. (Filha 2)

A doença, ao se apresentar como uma facticidade retirou os sujeitos de sua familiaridade e os fez adentrar em um mundo novo, marcado por tratamentos e restrições. Deve-se considerar que ao decidir agir-emfunção-de, o ser tende a uma posição determinada por uma situação que precede a decisão e que se reestrutura para e pelo sujeito da decisão, a partir do momento que, junto ao outro, atualiza seu projeto existencial em decorrência da decisão tomada (Ayres, 2004; Seibt, 2008). No presente estudo, os cuidadores dos homens em tratamento oncológico encontraram em seus laços familiares com o paciente a situação precedente à decisão e esta modificou seu projeto existencial inicial, pois, ao decidirem ser cuidadores, passaram a viver em função do paciente.

O trabalho é apontado como uma das principais restrições, entretanto deve-se considerar que, neste estudo, os participantes apresentaram uma renda média familiar em torno de dois salários mínimos, o que talvez possa explicar a grande ênfase no abandono do trabalho em razão da atividade de cuidar. Os participantes desse estudo, ao decidirem ser cuidadores, reestruturaram seus projetos existenciais em função do

1 Dasein: termo alemão traduzido para o português como ser-aí, caracterizando a existência e ressaltando sua condição de "estar lançado" no mundo 
"ser-adoecido". Ao se considerar que o Dasein é essencialmente em função dos outros, pois a preocupação se revela como modo primordial de sercom-os-outros, têm-se contida a responsabilidade de assumir seu ter-que-ser, ocupando-se do mundo e preocupando-se com os outros (Martins Filho, 2010).

Em seus discursos, os cuidadores relatam que se encontram-se de tal forma "pré-ocupados" com o outro que chegam até mesmo a se sentirem adoecidos:

[...] A gente sente como se tivesse com ela também (a doença), porque você tá ali na luta todo dia. Cada soro que ele toma na veia eu sinto na minha também. Cada soro que ele toma ali, cada picada é uma no meu braço também. (Esposa 2)

Esse envolvimento, que chega a sentir a dor do outro, só é possível porque esse outro é alguém significativo para o cuidador. A relação com o "serdoente" sempre afeta de alguma maneira a existência daquele que cuida, pois só cuidamos do outro quando a existência desse outro tem significado para nós (Critelli, 1996; Souza \& Boemer, 2005).

Os participantes deste estudo priorizam o cuidado ao paciente:

Porque no momento eu posso tá até precisando de uma ajuda, mas não como ele. Eu tenho que tá bem, eu tenho que ficar bem, eu tenho que ficar bacana, bonitinha, chique pra ele. Pra poder cuidar dele, né? [...] Fico de segunda a segunda. Fico sem tomar banho, fico sem comer, fico na... na coisa, mas to ai [...] Com esse tipo de problema a gente tem que se anular, se ignorar, você entendeu [...] Cuida só dele. Esquece de você. Mas cuida de você assim, alimenta dorme, procura relaxar, não procura ficar pegando outros problemas pra você não acarretar mais problema, pra você poder ficar com a mente boa pra poder ajudar. (Esposa 2)

Ao se assumirem cuidadores, mesmo tendo a consciência de que precisam de ajuda, os sujeitos priorizam o cuidado ao outro. Segundo Critelli (1996), o homem individual ou coletivamente escolhe o que vai estar sob seus cuidados, aproximando-se ou afastando-se da cotidianidade de seu mundo vivido. Mesmo que o Dasein decida não cuidar de si, essa atitude já constitui uma forma de cuidado "descuidada", que não deixa de ser um cuidado, pois não há como existir sem cuidar do que quer que seja. $\mathrm{Na}$ fala anterior, ao apontar que os cuidadores devem se esquecer de si mesmos para pensar só no paciente, a participante aponta para esse cuidado de si que se apresenta sob a forma de "descuido".

O cuidado "descuidado" de si também envolve a dimensão subjetiva dos cuidadores:

[...] Ai en fui em casa, ai en senti, eu chorei e tal, en desabafei [...] se en tiver triste ele vai ficar triste também. Ele vai achar que tá morrendo. Eu tenho que ficar sempre bem, né?’. (Esposa 3)
[...] estresse mesmo e esse estresse nunca que a gente pode passar pra eles. [...] Tem hora que a gente chora, mas longe dele. Sempre perto dele a gente tá rindo, eu to rindo, eu to contando. [...] Se ele vê a gente triste, fica, mas a gente nunca demonstra. A gente pode ficar triste, igual a gente sabe, o médico passou pra nós o estado dele, aí a gente chega perto dele sempre brincando, rindo. [...] Então a gente chora com os outros e ri com ele. (Filha 3)

[...] a gente via que ele ficava bem triste, mas a gente sempre tava lá em cima, né? A gente fazia força pra ele não perceber que a gente tava triste, né? [...] Eu chorava escondida, assim rezando e tudo, mas eu nunca deixei ele perceber que a gente tava muito preocupada com ele. (Filha 1)

Em muitos momentos, sentimentos como medo da possibilidade de morte do outro e até mesmo cansaço físico e subjetivo advêm. No entanto, perto dos pacientes, os cuidadores procuram sempre demonstrar que as coisas estão bem, mesmo quando não estão. Os discursos dos cuidadores estão em consonância com a literatura que aponta que o estado emocional dos cuidadores afeta o estado emocional dos pacientes (Rezende \& cols., 2005, Tavares \& Trad, 2009). Esse não poder compartilhar com o paciente seus medos e angústias faz com que os cuidadores tenham a necessidade de ter alguém pra desabafar.

Outra restrição apontada pelos cuidadores foi a solidão:

A gente sofre também. A familia afasta, os amigos. [...] Hoje, tirando eu e meus três filhos e a minha irmãa, não tem mais ninguém não. [...]. Mas a gente fica muito só, sabe? Igual no meu caso é eu e ele, ele e eu, é men companheirinho. [...] Que a gente também a gente não tem de tempo de conversar, não tem tempo de desabafar. [...] Que tem muitas coisas que não posso falar com ele, não posso desabafar com ele, não posso compartilhar com ele. Ai tem hora que você sente. [...] é uma coisa que eu fico pra mim, eu não vou falar pra ele, pra não preocupar ele, pra não... então aí você se sente só. (Esposa 2)

Em seus discursos, os cuidadores apontam que, pela falta de tempo, dentre outros fatores, se afastam do convívio social, ou as pessoas se afastam deles, o que faz com que os cuidadores se sintam sós. Diante este cenário, faz-se necessário discutir sobre a importância da escuta aos cuidadores de pacientes com câncer. Muitas vezes, os profissionais de saúde, por causa da dinâmica de seu trabalho, se preocupam com o paciente, ficando seu cuidador à margem das ações de saúde. Escutar os cuidadores, oferecer a eles esse momento para o desabafo de seus medos e ansiedades se faz importante para auxiliá-lo na adaptação e aceitação de seu novo projeto existencial, através da ressignificação da situação vivenciada (Almeida, \& cols., 2010).

Psico-USF, Braganca Paulista, v. 18, n. 3, p. 469-478, set/dez 2013 
Estudos apontam que o diagnóstico de câncer provoca uma ruptura na vida da pessoa adoecida (Hou, Law \& Fu, 2010). Neste estudo, pode-se constatar que também os cuidadores vivenciam essa ruptura existencial, pois em seus discursos relatam somente o adoecimento e tratamento de seus familiares.

Observa-se que os entrevistados procuram esquecer sua vida antes de se tornarem cuidadores e evitam pensar no futuro, pois temem mais sofrimento:

[...] a vida a gente tem que viver o boje, não tem que ficar pensando no que pode vim [...] É viver o hoje pra ficar tranquilo [...] O que aconteceu não tem como mudar. Eu penso dagora pra frente. (Filha 1)

[...] Cada dia é único pra nós. Nós não sabemos se amanhã nós vamos ter ele vivo. Então cada dia nós vivemos o melhor possivel com ele. (Filha 3)

[...] Eu acho que o futuro é... nem sei. À Deus pertence. O futuro é quando? O futuro é hoje? Não sei o que é o futuro. Então, en não preocupo com o futuro, né? Eu preocupo assim, igual agora ele tá ali ob. [...] É isso que eu preocupo. Agora o amanhã ou depois o que acontecer é isso mesmo. [...] Da minha vida pra trás eu não quero lembrar dela. Acabou, deixa ela pra trás, você tá entendendo? A gente tem que viver é o agora. [...] Eu to vivendo uma outra vida. A vida que eu vivi en esqueci dela. (Esposa 2)

A unidade originária da estrutura do cuidado é a temporalidade. Ao cuidar das coisas o Dasein se dispersa no presente, fazendo com que o cuidado se torne um incessante voltar-se sobre o agora. A ação presente de cuidar é configurada pela possibilidade futura da morte do outro (Seibt, 2008). Assim, se preocupar com o presente e não pensar no futuro constitui uma tentativa de evitar o sofrimento da perda do outro. A tentativa de esquecer momentos passados, em que a doença e a jornada do câncer não faziam parte de suas vidas, possibilita a aceitação da situação vivenciada.

Em seus discursos, os cuidadores apresentam medos relacionados principalmente ao bem-estar do paciente:

[...] Medo de acontecer alguma coisa assim, com ele, de repente, lá no momento e eu não poder fazer nada. (Filha 1)

Eu tenho medo dele não ter o conforto da minha parte. Dele não tá feliz, dele não tá bem, dele não... faltar alguma coisa pra ele assim, da minha parte, entendeu? [...] Mas deu... medo assim, de Deus me livre e guarde den adoecer e não poder cuidar dele direitinho igual eu cuido, né? [...] Por que eu tenho medo de que através, as vezes, de uma água que en dou de bicarbonato en ter que parar com ele aqui, ai eu matei ele pronto. (Esposa 2)
A possibilidade de vir-a-ser cuidador foi apresentada e os participantes do estudo a acolheram e assumiram. No entanto, não receberam informações sobre as formas como o cuidado pode ser realizado de uma forma a auxiliar tanto os pacientes quanto a si mesmos. A preparação dos cuidadores deve ser realizada não somente no sentido de prepará-los para os cuidados técnicos, mas também para o cuidado voltado para as questões subjetivas (Almeida \& cols., 2010).

Em sua missão, os cuidadores são exigidos a suportar junto ao paciente o sofrimento num encontro capaz de guardar os sentidos da existência do sujeito (Maffioletti, Loyola \& Nigri, 2006). Assim, as ações voltadas para a preparação dos cuidadores devem considerar a necessidade de valorizar seu modo de ser cuidador, os sentidos atribuídos ao processo de cuidar e as formas como o cuidado é realizado, para que, juntamente com os atores desse processo, as intervenções considerem os aspectos físicos, psíquicos e sociais envolvidos em sua realidade (Almeida, Savassi, Schall \& Modena, 2012).

Diante de toda essa situação de possibilidade de perda do ente querido e de "viver-em-função-dooutro", os cuidadores utilizam algumas formas de enfrentamento para lidar com a realidade vivenciada. Uma dessas formas de enfrentamento se apresenta pela aceitação da experiência, numa tentativa de amenizar o sofrimento:

O que a gente tem que passar não põe na porta dos outros não [… (Esposa 3)

Eu acho que o sofrimento a gente tem que passar por isso mesmo, né? Todo mundo sofre, uns mais, outros menos. A gente pede a Deus pra melhorar, né? (Esposa 4)

Amo ele demais. É só en e ele. No mais você tem que aceitar a realidade, (...) Eu choro porque en sei que amanbã ou mais... ou depois o que vai acontecer. Mas en não quero pensar isso, você tá entendendo? Eu não quero pensar. Mas a realidade é essa.(...) Porque aquilo que é seu, você não deixa pra ninguém, porque ninguém vai resolver aquilo que é seu. (Esposa 2)

[...] O que Deus traşa pra todo mundo é isso. A pessoa marcou de passar a gente não pode tomar dele e passar pro outro. Se dá uma coisa pra mim en não posso passar pra você, né? (Filho 1)

Essa tentativa de aceitação da realidade constitui uma forma que os cuidadores encontraram para cuidarem de si, pois, assim, significam a experiência presente. A esperança da cura e até mesmo a aceitação do ser-para-a-morte constituem outras formas de enfrentamento da situação utilizadas pelos cuidadores:

[...] a gente pede Deus 'Ob Deus cura, cura o men pai.' Talvez não é essa cura que Deus vai fazer. Talvez o que 
Deus vai fazer pra ele é o melhor, que vai dar pra ele o descanso. [...] não é porque eu to falando assim que eu quero que o meu pai morra. Eu não quero que meu pai... mas eu queria que Deus curasse ele se fosse possivel, mas se não for possivel, que Deus desse o descanso de tanto sofrer [...] É difícil acreditar que a gente gosta da pessoa e a pessoa tá indo. (Filha 3)

[...] A única coisa que en precisava era que o médico chegasse perto de mim e falasse assim: "Ele está curado, não vai ter nada mais, nada, nada. Só saúde". Isso pra mim tá bom. Chão, fico sem almoço, sem banho, fico sem colchão, fico em pé a noite inteira, tudo pra mim tá bom. (Esposa 2)

Para os cuidadores, todo o esforço empreendido nesse novo projeto existencial, todo o cuidado-com-ooutro seria recompensado pela cura do paciente, ou quando esta não é possível, pela cessação do sofrimento. Ao vivenciarem com o paciente todo o processo do câncer, os cuidadores, diante do sofrimento do ente querido, começam a aceitar a morte como uma possibilidade da existência. Ao se perceber como um ser-para-a-morte, o Dasein defronta-se com a vida, afasta-se de opiniões convencionais e escolhe autonomamente como vai viver, libertando-se das diversas preocupações e se dispondo a viver sua vida (Seibt, 2008).

A espiritualidade foi outra forma de enfrentamento encontrada nos discursos dos cuidadores:

Se não é Deus na minha vida eu acho que eu não aguentava. (Filha 3);

Teve um dia que eu cheguei assim 'Oh Jesus não agüento mais não' parece que as forças vão acabando. [...] (Pai)

Tudo o que Deus faz pra nós tá bom, eu aceito". (Esposa 4)

Busca Deus, vai conversando com Deus, o conbecimento da palavra de Deus. Esquece o que en falo, o que o outro fala, preocupa com Deus, pede esclarecimento, que ele vai te dando o esclarecimento das coisas, entendeu? [...] Tem hora que eu falo assim: "Senhor me fortalece, não me deixa cair, não me deixa no chão, não me deixa abaixar a minha cabeça, me põe sempre de cabeça erguida. Sempre fortalece as minhas pernas, os meus braços, a minha mente e o meu coração. Porque eu ainda tenho muito, mas muito ainda pra passar”. (Esposa 2)

A doença pode representar uma oportunidade de crescimento espiritual, uma vez que lembra ao sujeito sua fragilidade e traz questões sobre o propósito das coisas (Saad \& Nasri, 2008). Nos momentos mais difíceis do enfrentamento do câncer, as pessoas se voltam para a espiritualidade como forma de encontrar a esperança para a cura e como fonte de apoio para suportar os desafios provocados pelo tratamento e até mesmo para confrontarem-se diante da impossibilidade da cura (Salci \& Marcon, 2010; Souza, 2011). Assim, a crença em um ser superior torna-se uma importante fonte de apoio para o enfrentamento do câncer, auxiliando os cuidadores a suportar o isolamento social, o desgaste físico, financeiro e emocional que surgem a partir da tarefa de cuidar, além de ajudar os cuidadores a encontrar um sentido ao adoecimento do familiar e a aceitar a nova condição existencial, permitindo vivenciar essa fase de mudanças.

A fé também constitui um recurso poderoso para o fortalecimento dos vínculos e laços familiares uma vez que exerce um equilíbrio emocional, auxiliando no processo de aceitação e na busca de um significado para a situação (Di Primio \& cols., 2010, Fornazari \& Ferreira, 2010).

A esperança de retomar o projeto existencial inicial é apresentada pelos cuidadores por meio do término do tratamento oncológico: "[...] Ai agora que vai voltar a rotina normal" (Filha 1). Para os cuidadores, o término da quimioterapia apresenta-se como a cura da doença e encerramento de um período difícil de suas vidas, em que a rotina normal, a familiaridade foi perdida e agora pode ser novamente encontrada.

Para alguns cuidadores, a experiência de acompanhar o familiar com câncer durante o processo de adoecimento/cuidado pode ser ressignificada:

Cada dia que passa é uma novidade, cada dia que passa é uma coisa diferente. É uma surpresa. A vida é uma caixinha de surpresa [...] É a vida. (Esposa 2)

[...] A melhor escola que existe é o sofrimento, você sabe disso, né? É o que mais ensina a gente é o sofrimento. (Isaac)

É o que to aprendendo aqui, um ajudar o outro. (Esposa 4)

[...] antes eu ouvia falar câncer já era um choque assim pra gente assim, sabe? [...] Agora eu já me vejo assim, quando fala câncer eu já me vejo assim uma pessoa mais preparada pra poder tá lidando com o tratamento. (Filha 1)

[... essa doença, essa doença veio unir a família toda [...] Uma lição de vida. É uma lição pra dar mais valor a vida.

[...] Tá sendo uma lição, uma aprendizagem pra minha vida, minha filha. [...] Eu falo que essa doença do meu pai veio dar uma lição na família. E aqui no hospital a gente aprende a dar mais valor pra vida da gente. (Filha 3)

A doença, enquanto facticidade que coloca o homem diante de sua finitude, apresenta a fragilidade da vida, exigindo uma nova postura ante as situações. Essa nova postura será determinada pelo sentido que o sujeito atribui às mudanças. Assim, o desafio que toda doença impõe aos cuidadores de si mesmos e dos outros é a capacidade de termos uma presença viva e acolhedora (Deliberador \& Villela, 2010). A ressignificação da vivência de cuidar de um homem 
com câncer, apresentada pelos cuidadores, demonstra a capacidade acolhedora dos sujeitos.

Para Minkowski (2001), retirar do ser humano a possibilidade de adoecimento é retirar-lhe a possibilidade de reflexão, pois a doença se apresenta como um convite a um reposicionamento perante a vida ao perguntar-lhe por seu sentido. As famílias reconhecem que, ao vivenciar o câncer, pode-se conhecer melhor a existencialidade de ser-com-O-serdoente. Assim, a doença possibilita o fortalecimento dos laços familiares e a percepção de que a experiência do câncer pode ser uma lição de vida, fazendo com que valores materiais cedam lugar aos valores afetivos (Di Primio \& cols., 2010; Souza, 2011).

\section{O sentido do cuidar do homem com câncer}

Para alguns cuidadores, o fato de o paciente ser homem não se apresenta como um fator importante para suas práticas de cuidado:

Não. O mais importante é o amor" (Esposa 2); "[...] a mesma coisa.[...] Pra mim o mesmo cuidado que tenho com ele, tenho com a minha mãe." (Filha 3)

A mesma coisa. Pra gente que é esposa, que é filho, acho que isso aí não tem diferença se é homem ou se é mulher não. O que manda aí é mais o amor pela pessoa que a gente gosta. (Esposa 3)

Para esses cuidadores, o apoio oferecido ao familiar apresenta-se como o mais importante em suas práticas de cuidado. A manifestação do amor nas práticas de cuidado intensifica as relações familiares, fortalecendo os vínculos e facilitando a adaptação da família à cronicidade da doença (Caetano, Fernandes, Marcon \& Decesario, 2011).

Apesar de em seus discursos sobre o cuidado ao homem com câncer alguns cuidadores ressaltarem que o amor e o carinho são fatores importantes para o cuidado, outros cuidadores afirmam que o sexo da pessoa cuidada apresenta-se como um fator que merece destaque:

[...] é diferente. É teimoso [...] tem que ter muita paciência

(?) A mulher é mais fácil, né? Eu acho. (Esposa 4)

[...] às vezes fica agressivo, não aceita que fala as coisas, xinga. (Esposa 3)

Não tem nada a ver não. Todos os dois é homem, né? (Se fosse uma mulher?) Ai já era mais complicado. A gente ia sentir mais vergonha. (Filho 2).

Esses dados corroboram estudos que apontam que homens e mulheres vivenciam de maneiras diferentes o adoecimento por câncer e o tratamento oncológico. Xavier e cols. (2010) apontam que homens e mulheres demonstram comportamentos diferentes para lidar com a nova condição de saúde, bem como percebem a saúde de formas diferentes, o que gera impacto nas estratégias que utilizam para cuidar de si. As estratégias de enfrentamento do câncer utilizadas por homens e mulheres foram estudadas por Gianini (2007). Para o autor, enquanto os homens apresentam dificuldades de expressar os sentimentos e de se apropriar de suporte social, as mulheres mostraram mais expressões de sentimentos e mais confortáveis em buscar apoio da família e dos amigos.

A compreensão do Dasein como um ser que tem que realizar sua existência implica considerar o contexto em que foi lançado (Seibt, 2008). Assim, em se tratando do cuidado para os homens, deve-se considerar as especificidades do adoecer para essa população, pois as possibilidades oferecidas pelo mundo ao modo de ser dos homens são diferentes daquelas oferecidas para as mulheres. $\mathrm{O}$ adoecimento por câncer contradiz as representações que os homens têm a respeito da masculinidade, pois revela sua vulnerabilidade ante o adoecimento, o coloca diante de limitações físicas e sociais, apresentando suas fragilidades e a necessidade de cuidados, o que até então era associado ao feminino (Gannon, GuerroBlanco, Patel \& Abel, 2011; Mesquita, Moreira \& Maliski, 2011). Assim, é recorrente que esses sujeitos experienciem sentimentos de redução da autonomia, perda da independência, contribuindo com a ideia de perda da masculinidade (Gannon \& cols., 2010).

\section{Considerações finais}

Enquanto facticidade, o adoecimento por câncer modifica não só o projeto existencial daquele que adoece, mas também de todo o seu meio familiar. Ao escolherem cuidar do familiar adoecido, os cuidadores tiveram que ressignificar a doença, seus projetos existenciais e as formas de se cuidar do homem. Os cuidadores ressaltam que cuidar do homem é diferente, pois as possibilidades existenciais do ser homem, permeadas pela construção social da masculinidade, influenciam na forma de vivenciar o adoecimento e o cuidado.

Compreender como os cuidadores atribuem sentido às experiências vivenciadas nesse novo contexto de suas vidas faz-se importante para que se reflita sobre as ações de cuidado a esses sujeitos. Assim, conhecer os sentidos que os cuidadores atribuem ao seu fazer possibilita aos profissionais de saúde pensar em intervenções mais direcionadas às suas necessidades, visando melhorar não só sua qualidade de vida durante a prestação do cuidado, mas também a dos pacientes.

O presente estudo possibilita pensar em algumas questões: Há diferença de percepção das necessidades de cuidado ao homem em tratamento oncológico entre cuidadores formais e informais? Será que o poder 
aquisitivo do cuidador influencia no sentido atribuído à experiência de cuidar? O grau de dependência que a doença acarreta no paciente influencia nas percepções e sentidos dos cuidadores? Essas e outras tantas questões que ainda venham a surgir precisam que novos estudos sejam realizados a fim de aprofundar os conhecimentos sobre as especificidades do cuidado ao homem com câncer.

\section{Referências}

Almeida, S. S. L., Rezende, A. M., Schall, V. T. \& Modena, C. M. (2010). Os sentidos da corporeidade em ostomizados por câncer. Psicologia em Estudo, 15(4), 761-769.

Almeida, S. S. L., Savassi, L. C. M., Schall, V. T. \& Modena, C. M. (2012). Maternidade e hanseníase: as vivências de separação no isolamento compulsório. Estudos de Psicologia, 17(2), 27-81.

Ayres, J. R. C. M. (2004). O cuidado, os modos de ser (do) humano e as práticas de saúde. Saúde $e$ Sociedade, 13(3), 16-29.

Barbosa, L. N. F., Francisco, A. L. \& Eken, K. H. (2007). Adoecimento: o ser-para-a-morte e o sentido da vida. Pesquisas e Práticas Sociais, 2(1), 5460.

Breakwell, G. M. (2010). O uso do autorregistro: métodos de diário e de narrativa. Em G. M. Breakwell, S. Hammond, C. Fife-Schaw \& J. A. Smith. Métodos de pesquisa em psicologia. (pp. 260277). ( $3^{a}$ ed.). Porto Alegre: Artmed.

Caetano, J. P. M., Fernandes, M. V., Marcon, S. S. \& Decesario, M. N. (2011). Refletindo sobre as relações familiais e os sentimentos aflorados no enfrentamento da doença crônica. Ciência, Cuidado e Saúde, 10(4), 845-852.

Critelli, D. M. (1996). Analitica do sentido: uma aproximação e interpretação do real de orientação fenomenológica. São Paulo: Brasiliense.

Dazio, E. M., Sonobe, H. M. \& Zago, M. M. F. (2009). The meaning of being a man with intestinal stoma due to colorectal cancer: an anthropological approach to masculinities. Revista Latino-Americana de Enfermagem, 17(5), 664-669.

Deliberador, H. R. \& Villela, F. S. L. (2010). Acerca do conceito de saúde. Revista de Psicologia, 19 (2), 225 237.

Di Primio, A. O., Schwartz, E., Bielemann, V. L. M., Burille, A., Zillmer, J. G. V. \& Feijó, A. M. (2010). Rede social e vínculos apoiadores das famílias de crianças com câncer. Texto Contexto Enfermagem, 19 (2), 334-342.

Fornazari, S. A. \& Ferreira, R. E. R. (2010). Religiosidade/Espiritualidade em pacientes oncológicos: qualidade de vida e saúde. Psicologia: Teoria e Pesquisa, 26(2), 265-272.

Gannon, K., Guerro-Blanco, M., Patel, A. \& Abel, P. (2010). Re-construction masculinity following radical prostatectomy for prostate cancer. The Aging Male, 13(4), 258-264.

Ginaini, M. M. S. (2007). Câncer e gênero: enfrentamento da doença. Recuperado em 20 de setembro de 2012: http://www.psicologia.pt/artigos/textos/A0369.p df. Acesso em 03 de dezembro de 2012.

Heidegger, M. (2008). Ser e tempo. ( $3^{a}$ ed.). Petrópolis, RJ: Vozes.

Hou, W. K., Law, C. C. \& Fu, Y. T. (2010). Does change in positive affect mediate and/or moderate the impact of symptom distress on psychological adjustment after cancer diagnosis? A prospective analysis. Psychology and Health, 25(4), 417-431.

Maffioletti, V. L. R., Loyola, C. M. D. \& Nigri, F. (2006). Os sentidos e destinos do cuidar na preparação dos cuidadores de idosos. Ciência $e$ Saúde Coletiva, 11(4), 1085-1092.

Martins Filho, J. R. F. (2010). Heidegger: do ser-com ao ser-com-os-outros. Prometheus Filosofia em Revista, 6, 149-168.

Mesquita, M. G. R., Moreira, M. C. \& Maliski, S. L. (2011). "But I'm (became) different". Cancer nursing, 34(2), 150-157.

Minayo, M. C. S. (2007). O desafio do conhecimento: pesquisa qualitativa em saúde. São Paulo: Hucitec.

Ministério da Saúde/CNS (1996). Resolução no 196/96 Diretrizes e normas regulamentadoras de pesquisas envolvendo seres bumanos. Brasília: Ministério da Saúde.

Minkowski, E. (2001). La esquirofrenia, psicopatología de los esquizoides y de los esquizofrénicos. México: Fondo de Cultura Econômica.

Oliveira, M. F. V. \& Carraro, T. E. (2011). Cuidado em Heidegger: uma possibilidade ontológica para a enfermagem. Revista Brasileira de Enfermagem, 64(2) 376-380.

Rezende, V. L., Derchain, S. M., Botega, N. J. \& Vial, D. L. (2005). Revisão crítica dos instrumentos utilizados para avaliar aspectos emocionais, físicos e sociais do cuidador de pacientes com câncer na fase terminal da doença. Revista Brasileira de Cancerologia, 51, 79-87.

Saad, M. \& Nasri, F. (2008). Grupos de religiosidade e espiritualidade. Em E. Knobel (Org.). Psicologia e humanização: assistência a pacientes graves (pp. 349359). São Paulo: Atheneu.

Salci, M. A. \& Marcon, S. S. (2010). A convivência com o fantasma do câncer. Revista Gaúcha de Enfermagem, $31(1), 18-25$. 
Seibt, C. L. (2008). Ser-no-mundo em Ser e Tempo de Heidegger. Fragmentos de Cultura, 18 (7/8), 527-541.

Souza, M. G. G. (2011). Representações sociais do câncer para o familiar do paciente oncológico em tratamento quimioterápico. Dissertação de Mestrado, Programa de Pós-Graduação em Enfermagem, Universidade do Estado do Rio de Janeiro, Rio de Janeiro.

Souza, L. G. A. \& Boemer, M. R. (2005). O cuidar em situação de morte: algumas reflexões. Medicina, 38 (1), 49-54

Tavares, J. S. \& Trad, L. A. B. (2009). Famílias de mulheres com câncer de mama: desafios associados com o cuidado e fatores de enfrentamento. Interface, 13(29), 395-408.

Veras, L. (2009). O severino com câncer diante da morte: a morte na visão do sertanejo nordestino em tratamento oncológico. Dissertação de Mestrado. Centro de Ciências Humanas da Universidade de Fortaleza, Universidade de Fortaleza, Fortaleza.

World Health Organization. (2011). Cancer: palliative care. Recuperado em 20 de setembro, 2012. Organização Mundial de Saúde: http://www.who.int/cancer/palliative/en/.

Xavier, A. T. F., Ataide, M. B. C., Pereira, F. G. F. \& Nascimento, V. D. (2010). Análise de gênero para o adoecer de câncer. Revista Brasileira de Enfermagem, 63(6), 921-926.

Nota dos autores:

Agradecemos à Andréa Pereira Gazzinelli, pelo apoio aos pesquisadores no período das entrevistas.

Apoio financeiro de Fapemig e CNPq.

Sobre os autores:

Suellen Santos Lima de Almeida é psicóloga, mestre em Ciências da Saúde e doutoranda no Programa de PósGraduação em Saúde Coletiva, área de concentração Ciências Humanas e Sociais em Saúde, pelo Centro de Pesquisas René Rachou (Fiocruz Minas).

Alberto Mesaque Martins é psicólogo, mestrando em Psicologia (UFMG), professor substituto do Departamento de Psicologia da Faculdade de Filosofia e Ciências Humanas (FAFICH) da Universidade Federal de Minas Gerais.

Adryene Milanez Rezende é psicóloga, mestre e doutoranda no Programa de Pós-Graduação em Ciências da Saúde pelo Centro de Pesquisas René Rachou (Fiocruz Minas).

Virgínia Torres Schall é psicóloga, doutora em Educação e chefe do Laboratório de Educação em Saúde e Ambiente do Centro de Pesquisa René Rachou/ Fundação Oswaldo Cruz - Minas Gerais.

Celina Maria Modena é psicóloga, pós-doutora em Saúde Coletiva, pesquisadora visitante do Centro de Pesquisas René Rachou (Fiocruz Minas) e professora do curso de Programa de Pós-Graduação em Saúde Coletiva, área de concentração Ciências Humanas e Sociais em Saúde pelo Centro de Pesquisas René Rachou (Fiocruz Minas).

Contato com os autores:

E-mail: suellen@cpqrr.fiocruz.br-(31) 3349-7741 / 8724-4682 
